\title{
Detecção da proteína p53 em células leucêmicas por citometria de fluxo e Western blot*
}

\author{
Detection of p53 protein in leukemic cells by flow cytometry and Western blot
}

\author{
Geraldo Barroso Cavalcanti Júnior (MSc)', Marcos Antonio Mauricio Scheiner (MSc)², Flavia da Cunha Vasconcelos ${ }^{3}$, Jane de \\ Almeida Dobbin (MD) ${ }^{4}$, Claudete Esteves Klumb (MD, PhD) ${ }^{5}$, Raquel C. Maia (MD, PhD) 6 .
}

\begin{abstract}
Resumo
Introdução: A proteína p53 desempenha uma função crucial no controle do ciclo celular, reparo do D NA e na indução de apoptose em células geneticamente instáveis. 0 Western blot (W B) é o método preconizado para detecção dessa proteína, no entanto é técnica demorada e trabalhosa. Atualmente, a citometria de fluxo (CF) também tem sido empregada na detecção da proténa p53 tendo a vantagem da praticidade. 0 bjetivos e M etodologia: Comparar os resultados obtidos pela CF e W B na detecção da proteína p53 em células leucêmicas. Empregamos amostras de 3 pacientes com leucemia linfóide aguda (LLA), 5 com leucemia mielóide aguda (LMA), 6 com leucemia mielóide crônica (LM C) e 8 com leucemia linfóide crônica (LLC). O s controles positivos (5) e negativos (4), para os dois métodos, foram linhagens de células leucêmicas. Juntamente com o controle de marcação negativa, na técnica de $C F$, utilizamos linfócitos de 40 doadores de sangue. $A$ análise pela $C F$ foi realizada após a marcação com anticorpo monoclonal anti-p53 e o W B por técnica convencional. Resultados e Conclusões: O bservamos concordância nos resultados em $82 \%$ das amostras leucêmicas e em $100 \%$ nas linhagens celulares. CF +/WB+ foram observados em pacientes com evolução desfavorável tais como na LLC / Síndrome de Richter, LM C em crise blástica e na maioria das LM A. Apesar do WB ser considerado um método padrão para a detecção da p53, nossos resultados indicam que a CF pode ser empregada satisfatoriamente na detecção dessa proteína em amostras leucêmicas.
\end{abstract}

Palavras-chave: Proteína p53; Western blot; Citometria de fluxo; Leucemia.

\footnotetext{
* Trabalho realizado no Laboratório de H ematologia Celular (LHCM) e M olecular do Serviço de H ematologia, H ospital do Cancer I, Instituto Nacional de Câncer (LHCM / HC-I / IN CA/RJ).

${ }^{1}$ Farmacêutico-Bioquímico, Professor assistente da disciplina de Imunologia C línica do D epartamento de Análises Clínicas e Toxicológicas da U niversidade Federal do Rio Grande do Norte (DACT / UFRN) e Doutorando do LHCM / HC-I / IN CA/RJ,

2 Farmacêutico-Bioquímico do LHCM / HC-I / INCA/RJ,

${ }^{3}$ Bióloga do LHCM / HC-I / INCA/RJ,

${ }^{4} \mathrm{M}$ édica do Serviço de $\mathrm{H}$ ematologia do HC-I / INCA/RJ

${ }_{5}^{5}$ M édica do Serviço de H ematologia e do LHCM / HC-I / INCA/RJ

${ }^{6} \mathrm{M}$ édica H ematologista e responsável pelo LHCM / HC-I / INCA/RJ.

Endereço para correspondência - R.C.M. Laboratório de H ematologia Celular e M olecular, Serviço de H ematologia, H ospital do Câncer I, Instituto N acional de Câncer / IN CA. Praça da Cruz Vermelha, 23, Centro, CEP: 20.230-130. Rio de Janeiro - RJ, Brasil. E-mail: rcmaia@inca.gov.br
} 


\begin{abstract}
Introduction: The p53 protein plays a crucial role in the cell cycle control, D N A damage repair and induction of apoptosis in genetically unstable cells. The Western blot is the most utilized methodology for p53 detection, but it requires lots of time to be executed and is a very elaborated technique. N owadays, flow cytometry (FC), a more practical technique is being used for p53 detection. O bjectives and methodology: to compare the results of p53 detection by FC and WB in leukemic cells. We used samples from 3 patients with acute lymphoid leukemia (ALL), 5 with acute myeloid leukemia (AML), 6 with chronic myeloid leukemia $(C M L)$ and 8 with chronic lymphoid leukemia (CLL). The positive (5) and negative (4) controls, used in both methods were leukemic cells lineages. Lymphocytes from 40 healthy donors were used as control for negative labeling in FC. The FC was performed after labeling with p53 monoclonal antibody and the W B by usual protocol. Results and conclusion: We verified agreement in the results in $82 \%$ of leukemic samples and in $100 \%$ of cell lineages. FC +/W B + results were observed in patients with poor prognosis such as in CLL / Richter Syndrome, CML in blastic crisis and in the majority of $A M L$. Although WB is considered as standard methodology for $p 53$ detection, our results show that $F C$ can be satisfactorily used for detection of this protein in leukemic cells.
\end{abstract}

Key words: p53 protein; Western blot; Flow cytometry; Leukemia.

\section{INTRODUÇÃO}

M utações e inativações do gene p53 são as alterações genéticas mais freqüentes nos tumores malignos humanos, ocorrendo em cerca de $50 \%$ das neoplasias ${ }^{1-3}$. N as hemopatias malignas, as alterações do gene p53 são observadas com menor freqüência do que em tumores sólidos, predominando nas doenças mais avançadas e com curso clínico desfavorável ${ }^{4-8}$.

A proteína p53 funcional (wild type ou wt) apresenta meia vida curta (10 a 20 minutos) e atua na regulação do ciclo celular, reparo do DNA e, dependendo da extensão da lesão, indução da apoptose das células geneticamente instáveis, mantendo desta forma a integridade do genoma ${ }^{1-4,}, 5,1,10$.

Uma grande parte das mutações observadas no gene p53 resulta na transcrição e acúmulo de uma proteína mutanteenão funcional (p53m), quepodeser facilmente detectada nas células neoplásicas através de métodos imunológicos. Por outro lado, a proteína p53wt raramente pode ser detectada na maioria dos tecidos normais, pois tem uma sobrevida efêmera, contrastando com a p53m que é estável e, por isso, detectável por várias metodologias ${ }^{1-5}$.

A proteína p53 pode ser detectada utilizando-se anticorpo monoclonal (AcM o) anti-p53 originando a formação do complexo antígeno-anticorpo possível de ser detectado, obedecendo-se as particularidades e complexidade de cada metodologia. Pode-se utilizar para tanto, amostras de cortes histológicos (imunohistoquímica / IH Q ) 4,5,11, células em suspensão (citometria de fluxo / CF) 4, 12-15, imprint de tecidos (imuno-citoquímica / IC Q) ${ }^{4,16}$ ou lisados celulares (Western blot / W B) 4, 17, 18.

$O$ W B éum método analítico que utiliza o al to poder de resolução da eletroforese em gel de poliacrilamida e a determinação do peso molecular da proteína em questão com a especificidade da imunoquímica ${ }^{19}$. As proteínas resultantes da separação eletroforética são transferidas do gel de poliacrilamida para uma membrana de nitrocelulose, imediatamente após a corrida eletroforética, e seguida da incubação com anticorpo primário e de uma segunda incubação com um anticorpo secundário conjugado a peroxidase. 0 sistema revelador contém uma substância que ao reagir com o conjugado emitirá luz. Essa membrana quando exposta a um filme radiográfico revela a presença da banda protéica específica para o AcM o empregado ${ }^{19}$.

O W B é um método de alta especificidade e sensibilidade, sendo a técnica referida como "padrão ouro" para a detecção de proté́nas. N o entanto, por se tratar de uma técnica demorada e com várias etapas de execução, sua aplicação prática tem sido dificultada principalmente quando se emprega um grande número de amostras. Por isso, sua utilização costuma ser restrita aos trabalhos de pesquisa, em detrimento de outras metodologias que são mais rápidas e de fácil execução ${ }^{17}$.

A CF tem se destacado como um método eficaz para a deteç̧ão de antígenos de superfície, intracitoplasmáticos e nucleares e pode ser utilizada na detecção da proténa p53 em células tumorai ${ }^{12-15,}$ 20, 32. Esta metodologia apresenta a vantagem de ser uma 
técnica semi-automatizada em que se pode processar e analisar, conjuntamente, um grande número de amostras em tempo reduzido ${ }^{20}$. Adicionalmente, a CF apresenta como vantagem a possibilidade da análise multiparamétrica, fornecendo informações adicionais tais como análise simultânea de dois ou mais antígenos além da quantificação antigênica ${ }^{20}$.

$\mathrm{N}$ a pesquisa da proteína p53 pela CF, as células são inicialmente permeabilizadas e posteriormente incubadas com AcM o anti-p53 conjugado a um fluorocromo ${ }^{12-15,20 .}$ Após este procedimento elas são introduzidas por aspiração no CF, e neste são conduzidas através de um fluxo de líquido isotônico até um compartimento denominado câmara de fluxo "flow cell". N esse compartimento, um feixe de raios laser incide sobre cada célula, sendo uma parte, bloqueado frontalmente ("Forward Scatter" ou FSC) e outra parte dispersada lateralmente ("Side Scatter" ou SSC). A fração FSC é relativa ao tamanho da célula e a SSC representa a complexidade intracitoplasmática, que nas células sanguíneas caracteriza a granulosidade interna ${ }^{20}$. Caso as células expressem o antígeno em estudo ela estará marcada com um anticorpo conjugado a um fluorocromo. $\mathrm{No}$ caso das mesmas expressarem outros antígenos para os quais inclui-se a incubação com diferentes anticorpos específicos, as células mostrarão diferentes combinações de anticorpos-fluorocromos. A incidência de raio laser sobre estes fluorocromos causará sua excitação e conseqüente emissão de luz de diferentes comprimentos de onda (por exemplo: isotiocianato de fluoresceína - verde; ficoeritrina - laranja) ${ }^{20}$.

0 objetivo desse trabalho foi detectar a expressão da proteína p53 em células leucêmicas utilizando duas metodologias distintas: CF eWB e correlacionando com os parâmetros clínicos e laboratoriais, tais como os estágios evolutivos.

\section{MATERIAIS E MÉTODOS}

\section{CAsuística}

Foram analisadas amostras de sangue periférico (SP) elou medula óssea (M O ) de 22 indivíduos com hemopatias malignas, atendidos no Serviço de $\mathrm{H}$ ematologia do $\mathrm{H}$ ospital de Câncer, Instituto N acional de Câncer (IN CA/RJ): 8 amostras de leucemia linfocítica crônica (LLC), 6 de leucemia mielóide crônica (LM C); 5 de leucemia mielóide aguda (LM A) e 3 de leucemia linfóide aguda (LLA). D as amostras procedentes de pacientes com LLC, 3 foram examinadas na ocasião do diagnóstico, 4 durante 0 tratamento e uma em transformação para síndrome de Richter (SR). N os indivíduos acometidos por LM C, um estava em fase crônica e 5 em crise blástica. D os 5 pacientes com LM A, 4 foram estudados na ocasião do diagnóstico e um estava em recaída. Os três casos de LLA foram estudados na ocasião do diagnóstico.

0 diagnóstico e a classificação das leucemias foram baseados em dados clínicos, hematológicos e pelos critérios de classificação citomorfológica proposto pelo grupo French-Americam-British (FAB) para 0 diagnóstico das leucemias agudas ${ }^{21}$, imunofenotipagem e citogenética convencional.

\section{LINHAGENS CELULARES - CONTROLES}

As linhagens de células leucêmicas humanas foram, mantidas em meio de cultura (RPM I-1640, Sigma), suplementadas com $10 \%$ de soro bovino fetal inativado (SBF, Biomast, Brasil), e mantidas em estufa com $5 \%$ de C02, segundo a recomendação do American Type Culture Collection (ATCC) ${ }^{22}$. As linhagens Raji ${ }^{23,24} \mathrm{e}$ $\mathrm{N}$ amalva ${ }^{24}$ que expressam a p53m e as linhagens M T-2 ${ }^{25}$ e C 91pl ${ }^{26}$, que expressam a p53wt foram utilizadas como controles positivos de expressão e as linhagens K562 26, 27 , Lucena ${ }^{26}$, D audi ${ }^{26}$, H L-60 ${ }^{26} 28-30$ e Jurkat 26 como controles negativos (Tabela I). Paralelamente,

Tabela I- Linhagens de células leucêmicas humanas empregadas como controle

\begin{tabular}{c|c|c|c|c}
\hline $\begin{array}{c}\text { Linhagem } \\
\text { Celular }\end{array}$ & Origem & $\begin{array}{c}\text { Proteína p53 } \\
\text { (expressão) }\end{array}$ & $\begin{array}{c}\text { Gene p53 } \\
\text { (status) }\end{array}$ & Referências \\
\hline HL-60 & Leucemia promielocítica & Negativo & Deleção & $26,28-30$ \\
\hline K562 & Leucemia mielóide crônica em crise blástica & Negativo & Mutada & 26,27 \\
\hline Lucena & Derivada da linhagem K562 & Negativo & NR & 26 \\
\hline MT2 & Leucemia de células T do adulto & Positivo & Selvagem & 25,26 \\
\hline C91pl & Leucemia de células T do adulto & Positivo & NR & 26 \\
\hline Raji & Linfoma de Burkitt & Positivo & Mutada & $23,24,26$ \\
\hline Namalva & Linfoma de Burkitt & Positivo & Mutada & 24,26 \\
\hline Daudi & Linfoma de Burkitt & Negativo & Mutada & 24,26 \\
\hline Jurkat & Linfoma linfoblástico de células T & Negativo & NR & 26 \\
\hline
\end{tabular}

N R: dados não citados na literatura consultada. 
utilizamos células mononucleares de 40 indivíduos sadios (doadores de sangue) para o estabelecimento do ponto de corte dos níveis de expressão da proteína p53 pela CF.

As amostras dos pacientes e doadores de sangue foram coletadas após os indivíduos ou seus representantes legais serem esclarecidos dos objetivos do presente trabalho e assinado o termo de consentimento pós-informado.

\section{MÉTODOS}

\section{Separação de células mononucleares}

Amostras de MO e SP foram coletadas em tubos heparinizados e as células mononucleares separadas em gradiente de densidade (Ficoll-H ypaque, 1077- Sigma). Após esse procedimento, as células mononucleares foram lavadas três vezes com solução fisiológica $(\mathrm{N} \mathrm{aCl}$ $0,9 \%$ ) e ressuspendidas em meio de cultura RPM I (RPM I 1640-Sigma), suplementado com $10 \%$ de soro bovino fetal (SBF-Gibco) sendo ajustadas para a concentração final de 1,0 × $10^{6}$ células $/ \mathrm{ml}$.

\section{Teste de viabilidade celular}

As células mononucleares foram incubadas em solução de azul de tripan (M erck) a 0,5\% em solução salina tamponada com fosfatos (PBS, pH 7,4), na proporção de $9 / 1$. Após homogeneização, a mistura foi observada ao microscópio óptico com objetiva de $20 \mathrm{X}$, sendo descartadas as amostras com viabilidade inferior a $80 \%$.

\section{Detecção da proteína p53}

A detecção da proteína p53 foi realizada pela CF e WB em suspensões e lisados de células mononucleares de amostras de pacientes leucêmicos, doadores sadios e de linhagens de células leucêmicas, com 0 AcM 0 antip53 (D 0-7, Dako, Carpintaria, CA, USA), que reconhece o epitopo $\mathrm{N}$-terminal da proteína p53 WT e mutada $13,17,26$.

\section{Citometria de fluxo}

A fixação e a permeabilização das células mononucleares foram realizadas, empregando-se a solução de lise celular da Becton-D ickinson (Becton Dickinson's FACS lysing solution, San José CA, U SA) ${ }^{31-34}$. A suspensão celular foi ajustada para a concentração $1,0 \times 10^{6}$ células $/ \mathrm{ml} /$ tubo e sobre a mesma, adicionada 1 $\mathrm{ml}$ da solução de lise previamente diluída a 10\% em água destilada, e incubada por 10 minutos à temperatura ambiente. Após esse período, a amostra foi centrifugada a $1.500 \mathrm{rpm}$ por 5 minutos. 0 sedimento foi ressuspendido em PBS-tween 20 ( $M$ erck) a 2\%, seguido de nova centrifugação a 1.500 rpm por 5 minutos. Após o descarte do sobrenadante, 0 sedimento foi ressuspendido em solução de PBS com 5\% de SBF e incubado por 30 minutos à temperatura ambiente, para bloquear as ligações inespecíficas. Após o descarte do sobrenadante 0 sedimento foi ressuspendido em PBStween-20 e centrifugado a 1.500 rpm durante 5 minutos, seguido pelo descarte do sobrenadante. Ao sedimento foi pipetado $10 \mathrm{ml}$ de AcM o anti-p53 conjugado ao isotiocianato defluorosceína (FITC). A mistura foi então homogeneizada eincubada por 30 minutosà temperatura ambiente eao abrigo da luz. A pós essa etapa, o sedimento foi ressuspendido em solução de PBS-tween-20 a 0,5\% e centrifugado a $1.500 \mathrm{rpm}$ por 5 minutos, sendo esta etapa repetida mais uma vez. Em seguida, o sobrenadante foi descartado e ao sedimento foi adicionado $1 \mathrm{ml}$ de PBS com formalina (M erck) a $1 \%$, preservando à temperatura de 4으 $\mathrm{C}$ ao abrigo da luz até o momento da análise no CF. Para cada amostra testada foi utilizado um controle de marcação inespecífica (IgG 1-FICT, DAKO, Carpintaria, CA, USA).

As leituras e as análises foram realizadas no C F (Fluorescence Activated Cell Analyser - FACScan da Becton Dickinson, San-J ose, Ca, USA), utilizando-se o Cell Q uest software, versão 3.1 (C ell Q uestTM Software, Becton D ickinson immunocytometry systems, San J ose, CA, USA) com aquisição de 40.000 eventos, utilizandose uma janela de análise (gate) a partir dos parâmetros FSC e SSC. A partir do gate das células em estudo, obtivemos histogramas de intensidade de fluorescência do FITC, em escala logarítmica fornecida pelo CF, que varia de 0 a 104 log da fluorescência dos tubos contendo células marcadas com o AcM o e respectivo controle isotípico (Figura 1)

O s resultados foram fornecidos na forma de percentagem de células positivas, e de forma quantitativa determinados pela intensidade média de fluorescência razão entre a intensidade média de fluorescência (IM F) da amostra em estudo e do respectivo controle negativo ${ }^{15,26}$ e o valor D do teste de Kolmogorov-Smirnof (teste KS) ${ }^{35,36}$.

\section{Western blot}

Preparo das amostras

As amostras foram preparadas por lise direta de $10^{6}$ células, em $20 \mathrm{ml}$ de tampão de lise (10 mM EDTA, 60 $\mathrm{mM}$ de pirofosfato, $40 \mathrm{mM}$ tris- $\mathrm{HCl} \mathrm{pH} 6,8$ ), acrescida de $20 \mathrm{ml}$ de SD S (solução a 10\%) e $20 \mathrm{ml}$ de tampão de amostras (115 mM tris-H Cl pH 6,8; 15\% SD ; $10 \%$ de glicerol; $100 \mathrm{mM}$ de 2-b-mercaptoetanol; 0,1\% de azul debromofenol) eincubadas a 950C por 10 minutos, sendo mantidas a -200C até serem usadas.

\section{Eletroforese de proteínas}

Para cada amostra, $2 \times 10^{6}$ células foram submetidas a uma eletroforese em gel SD S-PAGE (acrilamida/bisacrilamida 29:1), sendo o gel de separação a 12\% 
Figura 1 - Expressão da proteína p53 por citometria de fluxo em amostras de pacientes leucêmicos.

As amostras foram incubadas com anticorpo monoclonal (AcMo) I anti-p53 conjugado ao FICT. Coluna da esquerda: representação gráfica das características físicas das células determinadas pelo espalhamento luminoso. O FSC (forward scatter) representa o tamanho das células e SSC a complexidade interna das células. Coluna do meio: expressão da proteína p53 avaliada através da relação da intensidade média de fluorescência (IMF) das células marcadas com o AcMo anti-p53 e células da mesma amostra incubadas com anticorpo isotípico e também pelo percentual de células p53 positivas. Coluna da direita: representação gráfica do teste Kolmogorov-Smirnov.

LMA: leucemia mielóide aguda; LLC/SR: leucemia linfocítica crônica em transformação para Síndrome de Richter e LLA: leucemia linfóide aguda.
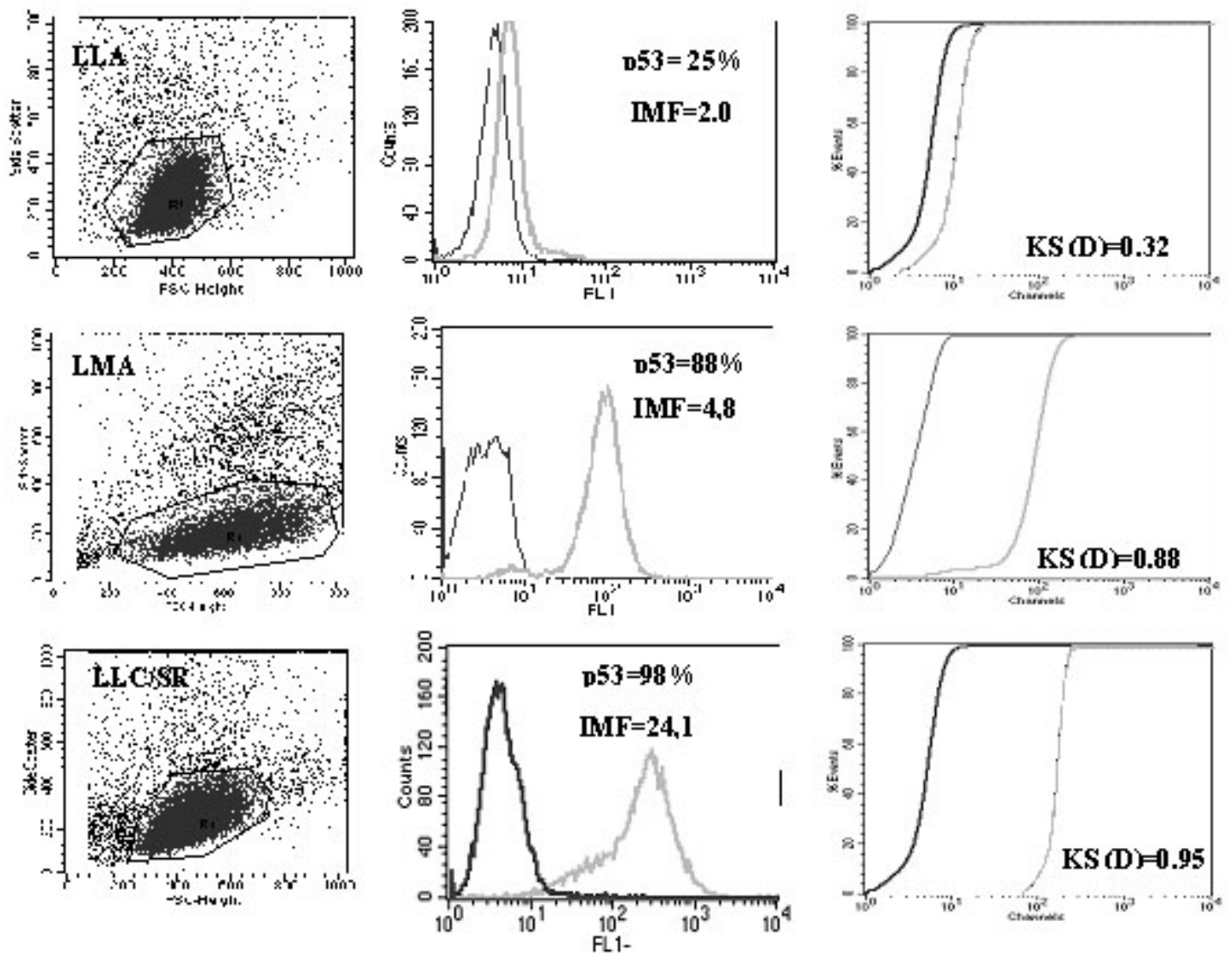

preparado em tampão contendo $1,5 \mathrm{M}$ tris- $\mathrm{H} \mathrm{Cl} \mathrm{pH} \mathrm{8,8}$ e $0,4 \%$ de SD $S$ e o gel de empilhamento (stacking gel) a $3 \%$ em tampão 0,5 M tris-HCl pH 6,8 e 0,4\% de SDS. A composição do tampão de eletroforese foi $25 \mathrm{mM}$ de tris $\mathrm{HCl}$ pH 8,3, $200 \mathrm{mM}$ de glicina e $1 \%$ de SDS. A eletroforese das proteínas foi realizada a 70 Volts em gel $14 \mathrm{~cm} \times 16 \mathrm{~cm}$ com duração de 16 horas.

Transferência das bandas protéicas para suporte sólido

Após a eletroforese, as bandas protéicas foram transferidas para a membrana de nitrocelulose utilizandose tampão com $25 \mathrm{mM}$ de tris, $193 \mathrm{mM}$ de glicina e $20 \%$ de metanol. A transferência foi feita em cuba semiseca (H oeffer-Scientific), por 2 horas, sendo a amperagem estabelecida em função da área da membrana.

\section{Marcação AcMo anti-p53}

A pós a transferência das bandas de proténas, a membrana de nitrocelulose, foi incubada por 2 horas em uma solução constituída de leite em pó desnatado a $5 \%$ em tampão TBS (10 mM de tris- $\mathrm{HCl}$ pH 7,4 e 0,9\% de $\mathrm{NaCl}$ ), à temperatura ambiente sob agitação leve e depois lavada 2 vezes em tampão TBS-tween $0,2 \%$ por 10 minutos. Em seguida, a membrana foi incubada com 0 AcM o anti-p53 (clone D 0-7 DAKO), diluído 1/2000 em leite em pó desnatado a 5\% em tampão TBS, por 16 horas na temperatura de 2 a $8^{\circ} \mathrm{C}$.

Após este período, a membrana foi lavada 3 vezes (15 minutos em cada lavagem) em tampão T BS-tween 0,2\%, sob agitação leve em temperatura ambiente e incubada com 0 anticorpo secundário (goat anti-mouse IgG F(ab)2 
H RP - PIERCE), diluído 1/4.000 em leite em pó desnatado a $5 \%$ em tampão TBS, por 2 horas, à temperatura ambiente, sob agitação suave, e seguida de 6 lavagens (15 minutos em cada lavagem) em tampão TBS-tween.

\section{Revelação}

A banda da proteína p53 foi revelada utilizando-se o Kit ECL (AMERSHAM PHARMACIA BIOTECH), de acordo com as especificações do fabricante e exposição da membrana a um filme de raio X (M AM 0 M KODAK) por 10 minutos e revelação em máquina de raio-X (Kodak).

\section{ANÁLISES ESTATÍSTICAS}

As análises estatísticas foram feitas utilizando os testes do qui-quadrado $\left(\chi^{2}\right)$ empregando-se o software EPIIN FO 6.04 e a análise de variância (AN OVA) pelo software SPSS 9.0, tomando-se 0 valor de $p<0,05$ como estatisticamente significativo. Foram também construídos os gráficos de correlação linear comparando os diversos parâmetros obtidos na CF. O s valores $D$ do teste $K S$ foram obtidos no software do próprio citômetro de fluxo.

\section{RESULTADOS}

$\mathrm{N}$ as 40 amostras de doadores de sangue, observamos as seguintes variações: 0 a $4 \%$ de células positivamente marcadas; 1,0 a 1,4 nos valores do IM $F$ e resultados do teste KS (D) variando de 0,01 a 0,08. Resultados similares foram observados nas amostras de células das linhagens leucêmicas: H L-60, K562, Lucena, D audi e Jurkat.

$N$ as linhagens leucêmicas, constatamos uma correlação de $100 \%$ entre os resultados obtidos pelo WB e CF, com expressão positiva da proteína p53 nas linhagens $\mathrm{N}$ amalva, Raji, C91pl e M T2 e negativa nas linhagens H L-60, K562, Lucena, D audi e Jurkat. N essas linhagens, as análises da quantificação antigênica, obtidas pela $C F$, revelaram resultados variados para o IM F e valor $D$ do teste $K S$. $O$ s valores mais elevados, na maioria dos casos, foram observados nas células com p53 positiva pelo W B. Estes resultados, nas células com p53 negativa pelo $W B$, foram menores e similares aos observados nos linfócitos dos doadores sadios (Tabela II e Figuras $2 a$ e $2 b)$.

$\mathrm{N}$ as amostras dos pacientes leucêmicos, houve concordância de resultados na maioria dos casos $\left(P=0,002\right.$, teste $\left.\chi^{2}\right)$. O bservamos 9 amostras duplamente positivas ( $C F+/ W B+$ ) eduplamentenegativas (CF-/WB). Resultados discordantes, (CF+ / WB-) e (CF-/WB+), foram observados em 4 amostras. As amostras duplamente positivas foram aquelas correspondentes a uma evolução clínica desfavorável, como LLC/SR (1 caso), LM C /CB (4 casos), LM A (1 secundária e 2 de novo) e 1
Tabela II - Expressão da proteína p53 em linhagens de células leucêmicas pela citometria de fluxo e Western blot.

\begin{tabular}{c|c|c|c|c}
\hline \multirow{2}{*}{ Células } & \multicolumn{3}{|c|}{ Citometria de Fluxo } & Western blot \\
\cline { 2 - 5 } & $\%^{*}$ & IMF* $^{*}$ & $\mathrm{KS}(\mathrm{D})^{*}$ & Status \\
\hline HL60 & 0 & 1,0 & 0,01 & negativo \\
\hline K562 & 0 & 1,3 & 0,05 & negativo \\
\hline Lucena & 0 & 1,2 & 0,04 & negativo \\
\hline Jurkat & 0 & 1,0 & 0,01 & negativo \\
\hline MT2 & 87 & 3,5 & 0,85 & positivo \\
\hline C91 pl & 87 & 4,2 & 0,86 & positivo \\
\hline Raji & 93 & 51,3 & 1,00 & positivo \\
\hline Namalva & 93 & 42,4 & 0,93 & positivo \\
\hline Daldi & 3 & 1,1 & 0,04 & negativo \\
\hline
\end{tabular}

(*): média dos valores determinados pela realização dos testes em triplicata; $\%$ : percentual de células marcadas; IM F: intensidade média de fluorescência; KS (D): Valor D do teste Kolmogorov-Smirnov.

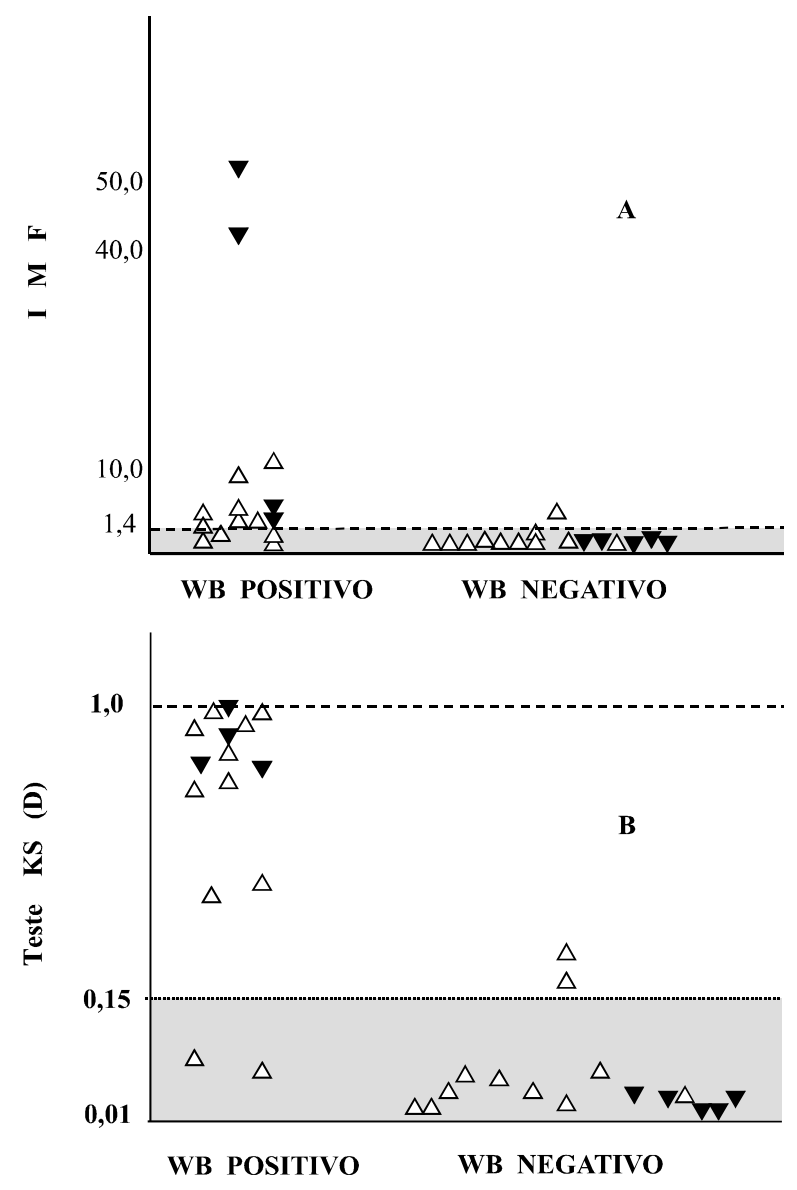

Figura 2- Distribuição dos valores do índice médio de intensidade de fluorescência (A) e valor $D$ do teste Kolmogorov-Smirnov (B) versus os resultados do Western blot em amostras de pacientes $(\Delta)$ e linhagens leucêmicas $(\boldsymbol{\nabla})$. Valores discriminados na área cinza, representam os resultados negativos. 
caso de LLA recém diagnosticada. Todas essas amostras apresentaram percentual elevado da expressão da proténa p53, juntamente com níveis elevados do IM F e valor D do teste KS (Tabelas III e IV).

Amostras duplamente negativas foram observadas em 5 casos de LLC (3 recém diagnosticadas e 2 em fase de acompanhamento terapêutico), 1 caso de LM C em crise blástica, 2 casos de LM A (1 de novo e 1 em recaída) e 1 de LLA recém diagnosticada. N esses casos, observamos que a expressão da proteína p53 foi similar nas amostras dos doadores e nas linhagens Jurkat, H L-60, K562, Lucena e $D$ audi, que foram utilizadas como controles negativos (Tabelas II e III e Figuras 2a e 2b).

Constatamos 4 amostras com resultados discordantes, 2 com CF +/W B- (1 LM C em FC e 1
LLA recém-diagnosticada) e 2 com CF-/W B + (2 LLC em acompanhamento terapêutico).

$\mathrm{N}$ as 2 amostras com resultados $\mathrm{CF}+/ \mathrm{W} \mathrm{B}$ - os parâmetros: IM F, valor $D$ do teste $\mathrm{KS}$ e percentual de células p53 positivas, foram menores, porém ainda acima do limiar de negatividade.

$\mathrm{N}$ as duas amostras com resultados $\mathrm{CF}-/ \mathrm{WB}+$, os resultados da CF são similares aos encontrados nas amostras duplamente negativas.

$\mathrm{N}$ a análise envolvendo a correlação linear entre os parâmetros IM F, valor $\mathrm{D}$ do teste $\mathrm{KS}$ e percentual de células p53 positivas, observamos uma tendência para correlação positiva entre esses parâmetros tanto no grupo de pacientes, como no grupo de doadores e linhagens celulares. Essa correlação foi positivamente acentuada, para

Tabela III - Expressão da proteína p53 em células leucêmicas por citometria de fluxo e Western blot.

\begin{tabular}{|c|c|c|c|c|c|c|}
\hline \multirow{3}{*}{ Paciente } & \multirow{3}{*}{ Diagnóstico } & \multirow{3}{*}{ Status } & \multicolumn{4}{|c|}{ Expressão da proteína p53 } \\
\hline & & & \multicolumn{3}{|c|}{ Citometria de fluxo } & \multirow{2}{*}{ Western blot } \\
\hline & & & $\%$ & IMF & $\mathrm{KS}(\mathrm{D})$ & \\
\hline 1 & LLC & transformada & $74 \%$ & 4,1 & 0,95 & Positivo \\
\hline 2 & LLC & diagnóstico & $0 \%$ & 1,0 & 0,01 & Negativo \\
\hline 3 & LLC & $\mathrm{TT}$ & $0 \%$ & 1,2 & 0,08 & Negativo \\
\hline 4 & LLC & $\mathrm{TT}$ & $0 \%$ & 1,2 & 0,09 & Negativo \\
\hline 5 & LLC & $\mathrm{TT}$ & $0 \%$ & 1,3 & 0,10 & Positivo \\
\hline 6 & LLC & $\mathrm{TT}$ & $1 \%$ & 1,3 & 0,13 & Positivo \\
\hline 7 & LLC & diagnóstico & $0 \%$ & 1,2 & 0,05 & Negativo \\
\hline 8 & LLC & diagnóstico & $0 \%$ & 1,0 & 0,01 & Negativo \\
\hline 9 & LMC & $\mathrm{CB}$ & $20 \%$ & 2,2 & 0,53 & Positivo \\
\hline 10 & LMC & CB & $98 \%$ & 11,9 & 0,98 & Positivo \\
\hline 11 & LMC & $\mathrm{CB}$ & $81 \%$ & 4,5 & 0,81 & Positivo \\
\hline 12 & LMC & $\mathrm{FC}$ & $35 \%$ & 1,5 & 0,39 & Negativo \\
\hline 13 & LMC & $\mathrm{CB}$ & $4 \%$ & 1,2 & 0,10 & Negativo \\
\hline 14 & LMC & CB & $54 \%$ & 2,1 & 0,56 & Positivo \\
\hline 15 & LMA & secundária & $96 \%$ & 10,0 & 0,99 & Positivo \\
\hline 16 & LMA & diagnóstico & $0 \%$ & 1,0 & 0,05 & Negativo \\
\hline 17 & LMA & de novo & $88 \%$ & 4,8 & 0,88 & Positivo \\
\hline 18 & LMA & de novo & $92 \%$ & 4,1 & 0,94 & Positivo \\
\hline 19 & LMA & de novo & $0 \%$ & 1,1 & 0,02 & Negativo \\
\hline 20 & LMA & de novo & $79 \%$ & 3,3 & 0,79 & Positivo \\
\hline 21 & LLA & de novo & $25 \%$ & 2,0 & 0,32 & Negativo \\
\hline 22 & LLA & de novo & $0 \%$ & 1,0 & 0,04 & Negativo \\
\hline
\end{tabular}

\%: percentuais de células marcadas, IM F: intensidade média de fluorescência, KS (D): Valor D do teste Kolmogorov-Smirnov; LLC: leucemia linfocítica crônica; LM C: leucemia mielóide crônica; LM A: leucemia mielóide aguda; LLA: leucemia linfóide aguda; CB: crise blástica; FC: fase crônica; TT: em tratamento. $\mathrm{P}=0,002$ 
os três grupos, quando utilizamos o percentual de células p53 positivas versus o valor $D$ do teste $K S$, onde sempre obtivemos um valor de R2 >0,90 (Tabela V e Figura 3).

Tabela IV- Análise de variância entre os resultados obtidos pela citometria de fluxo e Western blot em 22 amostras de pacientes leucêmicos

\begin{tabular}{c|l|c|c}
\hline Variável & \multicolumn{1}{|c|}{$\begin{array}{c}\text { Western blot } \\
\text { negativo } \\
\bar{X} \pm d p \quad n=11\end{array}$} & \multicolumn{1}{|c|}{$\begin{array}{c}\text { Western blot } \\
\text { positivo } \\
\bar{X} \pm d p \quad n=11\end{array}$} & $p$ \\
\hline$\%$ & $10 \pm 24,7$ & $57,9 \pm 37,9$ & 0,002 \\
\hline IMF & $1,22 \pm 0,30$ & $4,51 \pm 3,44$ & 0,005 \\
\hline KS (D) & $0,11 \pm 0,13$ & $0,70 \pm 0,33$ & $<0,001$ \\
\hline
\end{tabular}

\%: percentual de células positivas; IM F: índice médio de fluorescência; $\mathrm{KS}$ : teste de Kolmorogov-Smirnov. $\mathrm{X} \pm \mathrm{dp}=$ média \pm desvio padrão.

Tabela V- Parâmetros obtidos na citometria de fluxo em amostras dos pacientes, linhagens leucêmicas e doadores de sangue.

\begin{tabular}{c|c|c|c}
\hline Amostras & $\mathrm{R}^{2}$ & $\mathrm{R}^{2}$ & $\mathrm{R}^{2}$ \\
& $\mathrm{IMF} \times \mathrm{KS}(\mathrm{D})$ & $\% \times \mathrm{IMF}$ & $\% \times \mathrm{KS}(\mathrm{D})$ \\
\hline Pacientes, $\mathrm{n}=22$ & 0,62 & 0,67 & 0,99 \\
\hline Linhagens, $\mathrm{n}=9$ & 0,50 & 0,50 & 0,99 \\
\hline Doadores, $\mathrm{n}=40$ & 0,92 & 0,99 & 0,93 \\
\hline
\end{tabular}

\%: percentual de células positivas; IM F: índice médio de fluorescência; $\mathrm{KS}$ : teste de Kolmorogov-Smirnov; $\mathrm{R}^{2}$ : Teste de correlação linear
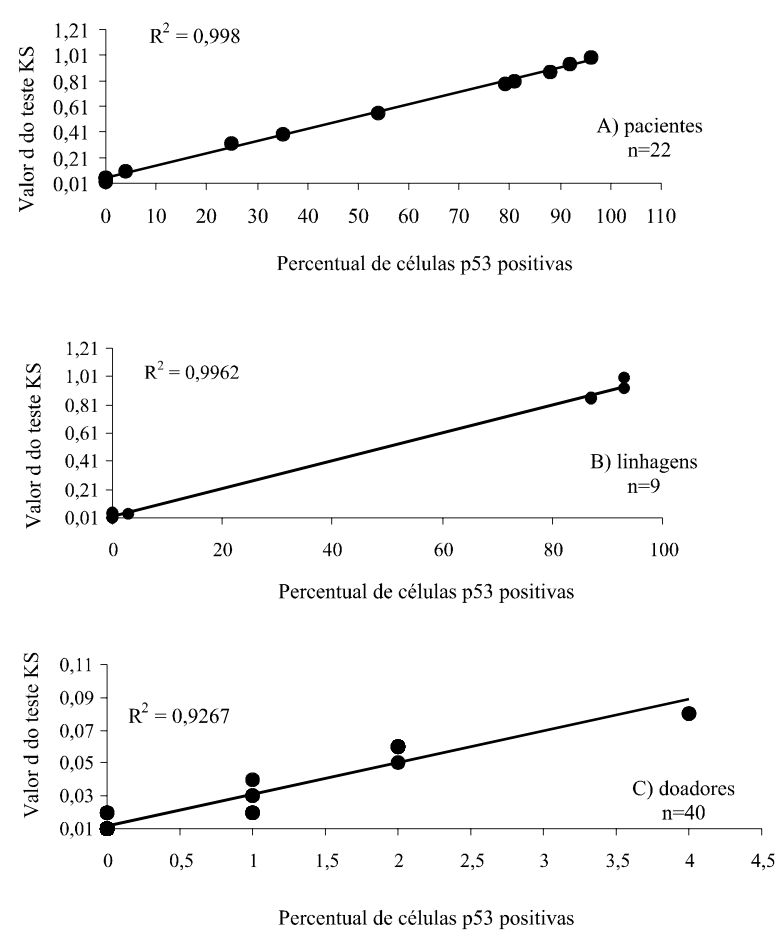

Figura 3 - Análise de correlação linear da expressão da proteína p53 com os diversos parâmetros obtidos na citometria de fluxo: A, amostras dos pacientes; B, amostras procedentes das linhagens de células leucêmicas e $C$, amostras dos doadores.

\section{DISCUSSÃO}

Embora as alterações do gene e proténa p53 ocorram com menor freqüência nas neoplasias do sistema hematopoético do que em tumores sólidos, diversos trabalhos têm destacado a relevância clínica das disfunções desse gene e / ou inativação de seu produto de transcrição. A associação entrea mutação e a superexpressão da proteína p53 e a evolução clínica desfavorável nas leucemias tem sido observada $5-8,12,14,28$. N essas neoplasias, mutações do gene p53 são encontradas em 25 a 30\% dos linfomas de Burkitt, na LM C em crise blástica em $25 \%$, em 5 a $10 \%$ das LM A, síndrome mielodisplásica (SM D ), linfomas não H odgkin (LNH) e LLC, exceto nas transformações para SR onde este percentual é mais elevado. Essas mutações são raramente observadas na LLA, exceto nas recaídas e no tipo citomorfológico $L 3$ 4-8, 12-14, 28 .

As mutações, em geral do tipo missense, podem ser demonstradas por técnicas moleculares como o single strand conformation polymorphism (SSCP) ou métodos de seqüênciamento de D N A ${ }^{45,11}$. No entanto, por serem metodologias dispendiosas e demoradas em que são necessárias várias etapas de processamento, sua utilização na rotina torna-se restrita, principalmente quando se processa um grande número de amostras. O utra limitação para o emprego dessas técnicas de biologia molecular, no estudo de mutações do gene p53 nas leucemias, é a freqüente contaminação das amostras por células não tumorais, levando a amplificação de alelos não mutados do gene p53 e a resultados falso-negativos, o que dificulta a realização e a interpretação desses resultados ${ }^{37,38}$.

Em nosso trabalho, investigamos a expressão da proteína p53 em linhagens de células leucêmicas, em células normais de doadores de sangue e em leucêmicas, comparando dois métodos de detecção: 0 WB e a CF.

$O$ WB é classicamente referido como método padrão ouro na pesquisa da proténa p53 em células tumorais. Porém, sua aplicabilidade na rotina laboratorial deve ser discutida em função de algumas particularidades desse método, como as numerosas etapas de processamento, 0 quedemanda um longo tempo para obtenção dos resultados, podendo também ser apontada como uma das causas de erro ${ }^{5,18,26}$. Há necessidade da utilização de diversos equipamentos de apoio e manipulação de substâncias químicas tóxicas e carcinogênicas. Esses fatores também podem ser tomados como indicadores para elevação dos custos e dificultam a sua aplicação na rotina laboratorial.

U Itimamente a CF tem se destacado como um método de detecção de antígenos de superfície e intracelulares, podendo também ser empregada na detecção da proteína p53 5, 12-15, 20, 26, 30. A marcação prévia de células com AcM 0 conjugado a diferentes fluorocromos possibilita a análise 
de uma célula com uma determinada característica física e/ou química, mesmo em amostras com diferentes populações celulares ${ }^{20}$. Estas peculiaridades da CF possibilitam o emprego dessa metodologia na área de imunologia e onco-hematologia, na caracterização de antígenos celulares, nasimunodeficiências ${ }^{39}$, no diagnóstico de processos leucêmicos ${ }^{31-34,40-42}$, na detecção da doença residual mínima ${ }^{43}$ e durante a evolução e tratamento dessas doenças ${ }^{31-34}$.

Para detecção da proténa p53 pela CF, conhecendo-se seus aspectosfisiológicos, procurou-seestabelecer um protocolo de fixação e permeabilização que possibilitasse 0 acesso e direcionamento do AcM o ao núcleo das células preservando, ao mesmo tempo, suas características físico-químicas ${ }^{12-15,26 .}$ Por se tratar de um procedimento semi-automatizado, a CF apresenta vantagens em termos de viabilidade de execução ao utilizar-se amostras recém obtidas e a reação imunológica se processar diretamente na própria célula.

Existem diferentes protocolos descritos na literatura com 0 emprego de metanol ${ }^{12,} 14,20$, saponina ${ }^{13,20}$, além de kits comerciais para lise e permeabilização celular ${ }^{20,26,31-34,44}$. Porém, o emprego desses reagentes em processos de permeabilização celular tem gerado resultados com eficiência controversa ${ }^{20,44}$. Farrat e colaboradores, em 1994¹ , descreveram um método de pesquisa de antígenos intracitoplasmáticos em células leucêmicas, preservando ao mesmo tempo, os sinais de difração de luz, a antigenicidade dos epitopos e 0 acesso dos anticorpos ao interior das células permeabilizadas. Este protocolo foi, recentemente, reproduzido com sucesso por nosso grupo na pesquisa da proteína p53 em linhagens de células tumorais, onde obtivemos uma correlação de $100 \%$ dos resultados com a ICQ e W B ${ }^{26}$. No presente estudo, esse protocolo foi empregado com modificações e observamos uma boa correlação com os resultados do W B em amostras de pacientes leucêmicos ( $P=0,002$ ) eem $100 \%$ nas amostras procedentes de linhagens celulares leucêmicas.

Existem várias formas de se avaliar os resultados na CF. Em nosso estudo, utilizamos: i) a percentagem de células p53 positivas ${ }^{26,39}$, ii) mudança do canal médio de fluorescência calculado pela razão entrea intensidade média de fluorescência (IM F) da amostra marcada com o AcM o e da respectiva amostra marcada com o controle isotípico $15,26,40$ e iii) 0 valor D do teste estatístico KolmogorovSmirnov (teste KS) ${ }^{35,36}$. 0 teste KS analisa e compara os histogramas, gerados pelas células que foram marcadas com - AcM o e as marcadas com o controle isotípico do ensaio. Ele mede a diferença entre as duas curvas de distribuição, gerando um valor $D$, sendo calculado pelo próprio software do $C F$, e considerado como positivo para os valores $D \geq 0,15^{35,36}$. Esse teste consegue detectar células pouco marcadas, identificando diferenças de fluorescência entre as amostrastestadas com o AcM o e células da mesma amostra marcadas com o controle inespecífico. D esta forma, quanto mais alto 0 valor $D$, maior será a diferença entre as curvas. Q uando $D$ for $>0,30$ a amostra será intensamente positiva, seo valor $D$ estiver entre 0,15 e 0,25 a intensidade antigênica será moderada, baixa quando 0 valor $D$ estiver entre 0,05 e 0,14 e ausência de fluorescência quando 0 valor de $D$ for menor que $0,0535,36$.

A reprodutibilidade desse método foi demonstrada em nosso trabalho, pela realização dos testes em triplicata nas linhagens leucêmicas e em linfócitos normais procedentes de 40 doadores de sangue. N essas amostras, estabeleceuse valores que serviram como parâmetros para definir um ponto de corte, visando identificar a expressão da proteína p53 pela CF. O bservou-se variação de 0 a $4 \%$ para 0 percentual de células marcadas; 1,0 a 1,4 nos valores do IM F e valores de $D$ do teste $K S$ variando de 0,01 a 0,08.

$\mathrm{N}$ aslinhagensleucêmicasK 562, Lucena, H L-60, D audi e Jurkat, que não expressam a proténa p53, obtivemos resultados similares aos observados em amostras dos doadores, com resultados negativos no W B. A linhagens Raji, N amalva, M T2 e C 91pl apresentaram percentual de células $\mathrm{p} 53$ positivas, IM F e valor $\mathrm{D}$ do teste $\mathrm{KS}$ superiores aos observados nas amostras dos doadores e nas linhagens, K562, Lucena, Jurkat, D audi e H L-60, correlacionandose com os resultados positivos no WB.

As amostras procedentes dos pacientes apresentaram níveis variáveis de expressão para a proténa p53 pela CF. Com os parâmetros obtidos por esse método foi possível fazer a correlação desses resultados com o W B, sendo encontradas 18 amostras com resultados iguais e 4 discordantes entre si $(P=0,002)$.

Amostras com resultados p53+ observadas no W B apresentaram, na maioria dos casos, elevado percentual de positividade associando-se aos níveis mais altos de IM F, e valor $\mathrm{D}$ do teste $\mathrm{KS}$, quando testadas pela CF. Esses casos corresponderam na maioria das vezes aos pacientes com doenças cuja evolução clínica era mais desfavorável tais somo: LLC/SR, LMC em CB e na maioria dos casos de LM A.

$\mathrm{N}$ as amostras com resultados discordantes ( $\mathrm{CF}+/ \mathrm{WB}$ ) foi observado um percentual menor de células p53t, bem como níveis mais baixos de IM F e valor $D$ do teste $K S$. Esses valores estão acima dos obtidos nas amostras dos doadores de sangue e linhagens p53 negativa (Lucena, D audi, Jurkat, K562 e HL-60). Esses achados associados às características metodológicas da $C F$, tais como simplicidade de execução, utilização de células recém obtidas e o fato da reação imunológica se processar na própria célula (marcação direta), pode refletir, uma maior sensibilidade da CF quando comparada ao WB, que apresenta além da necessidade de maior tempo de execução, a possibilidade da degradação da proteína p53 
por proteases, quando o material éestocado em temperatura inadequada ou por um tempo prolongado ${ }^{26}$.

Concluindo, os nossos resultados demonstraram que ambos os métodos de estudo: CF e WB são úteis na detecção da proteína p53 em células leucêmicas.

A CF pode ser uma metodologia mais adequada em função da simplicidade de execução, sensibilidade e fornecimento dos resultados em tempo inferior quando comparado com o W B. D esta forma, nossos resultados sugerem que a CF pode ser empregada no estudo da expressão da proteína p53 em células leucêmica.

\section{REFERÊNCIAS}

1. Beroud C, Soussi T. p53 genemutation: softwareand database. N ucleic AcidsRes. 1998;26(1):200-4.

2. Soussi T, D ehoucheK, Béroud C. L'analysedes mutations du gène p53 dans les cancers humains: le lien entre l'épidémiologie et la carcinogenèse. $M$ ed Sci Synth. 2000;16:1378-96.

3. M artin A. Legéne suppresseur detumeur p53 (2 ${ }^{\mathrm{a}}$ partie): applications en pathologie humaine. Ann Pathol. 1995;15(3):184-91.

4. Klumb CE, C avalcanti GB Jr. Avaliação dos métodos de detecção das alterações do geneeproténap53 nasneoplasias linfóides. Rev BrasH ematol H emoter. 2002;24(2):111-25.

5. Cavalcanti GB J r, Klumb CE, M aia RC. p53 eashemopatias malignas. Rev Bras C ancerol. 2002;48(3):419-27.

6. Fenaux P. The clinical significance of the $\mathrm{p} 53$ supressor gene in haematological malignancies. $\mathrm{Br} J \mathrm{H}$ aematol. 1997;98:502-11.

7. PreudhommeC, Fenaux P. p53 et hemopathies malignes. Pathol Biol. 1997;45(10):777-908.

8. ImamuraJ, M iyoshi I, Koeffler P. p53 in hematologic malignancies. Blood. 1994;84(8):2412-21.

9. JanusF, Albrechtsen N , D ornreiter I, W iesmüller L, G rosse F, D epper W. Thedual rolemodel for p53 maitaining genomic integrity. Cell M ol L Sci. 1999;55:12-27.

10. Yonish-Rouach $E$. A question of life or death: the p53 tumor supressor gene. Pathol Biol. 1997;45(10):815-23.

11. Klumb CE, Furtado D R, de R esende LM , C arriço M K, Coelho AM, de M eis $E$, et al. D N A sequence profile of TP53 genemutation in childhood B-cell non-H odgkin's lymphomas: prognostic implications. Eur J H aematol. 2003;71:81-90.

12. KonikovaE, Kuseuda O, Babusikoval. Flow cytometry of p53 protein expression in somehematological malignancies. N eoplasma. 1999;46(6):368-76.

13. Fillippini G, G riffin S, U hr M , Eppenberger H , BonillaJ, Cavalli $F$, et al. A novel flow cytometry method for the quantification of p53 gene expression. Cytometry. 1998;31:180-6.
14. K onikova E, Kuseuda O. Flow cytometry of p53 protein expression in somehematological malignancies. N eoplasma. 2001;48(4):290-8.

15. Kimura O , Sugamura K, KijimaT, M akino M, Shigeru T, I to $\mathrm{H}$, et al. Flow cytometry examination of p53 protein in primary tumors and metastases to the liver and lymphonodes of colorectal cancer. D is Colon Rectum. 1996;39(12):1428-33.

16. T iniakos D G, H ealicon RM , H air T, Wadehra V, H orne $\mathrm{CH}$ W, Angus B. p53 immunostaining as a marker of malignancy in cytologic preparations of body fluids. ActaCytol. 1995;39:171-6.

17. Bonsing BA, C over WE, Gorsira M CB, van Viet M, O ud PS, CornelisseCJ, et al. Specific of seven M onoclonal antibodies against p53 evaluated with Western blotting, immunohistochemistry, confocal laser scanning microscopy and flow cytometry. Cytometry. 1997;28:11-24.

18. Turpeinen M , Serpi R, Rahkolin M , VähäkangasK. Comparison of anti p53 antibodiesin immunoblotting. Biochem Biophys Res Commun. 2002;293:850-6.

19. M argni R, M ailchiodi EL, ChiaramonteM G. Electroforese en gel de poliacrilamida; isoelectroenfocado; inmunotransferencia (immunoblotting). In: M argni RA. Inmunologíaeinmunoquímica: fundamentos. 5aed. Buenos Aires: Editorial M édica Panamericana. cap. 21, p. 981-8.

20. M ark JJ, H eller R. M ethods in molecular biology: flow cytometry protocols. Totowa: H umana Press; 1988. vol. 91.

21. Bennett JM , Catovsky D , D aniel M T, Flandrin G , Galton D AG , G ralnick H R, et al. Themorphological classification of acute lymphoblastic leukaemia: concordance among observers and clinical correlations. $\mathrm{Br} J \mathrm{H}$ aematol. 1981;47:553-61.

22. American Type Culture Collection [homepage on the Internet]. [cited 2003 D ec]. Available from: http:// www.atcc.org.

23. D uthu A, D ebuire B, Romano J, Ebrhart J, Fiscella M , $M$ ay $E$, et al. p53 mutations in Raji cells: characterizations and localizations relative to other Burkitt's lymphomas. O ncogene.1992;7(11):2161-7.

24. Gaidano G, Ballerini P, G ong JZ, Inhirami G, N eri A, $\mathrm{N}$ ewcomb EW, et al. p53 mutation in human lymphoid malignancies: association with Burkitt lymphoma and chronic lymphocytic leukemia. Proc N atl Acad Sci U SA. 1991;88:5413-541.

25. M ahieux R, Pise-M asison CA, N icot C, G reen P, H all WW, Brady JN . Inactivation of p53 by H TLV typel and H TLVtype 2 Tax trans-Activators. Aids Res Hum Retrovir. 2000;16(16):1677-81.

26. Cavalcanti GB Jr, Scheiner M AM , O liveiraJ G P Vasconcelos FC, Ferreira ACS, M aia RC. Citometria de fluxo, imunocitoquímica eWestern blot na detecção da expressão da proteína p53 em células tumorais: uma análise comparativa. Rev BrasAnal C lin. 2003;35(3):135-42. 
27. Law JC, Ritke M K, Yalowich JC, Leder G H, Ferrell RE. $M$ utational inactivation of p53 genein thehuman erithroid leukemic K 562 cell line. Leuk Res. 1993;17(12):1045-50.

28. Prockocimer $M$, Shakai $M$, Ben Bassat $H$, Wolf $D$, Goldfinger N , Rotter V. Expression of p53 in human leukemia and lymphoma. Blood. 1986;68(1):113-8.

29. Siles E, Villalobos M , Valenzuaela M T, N úñez M I, G ordon A, M cM illan TJ, et al. Relationship between p53 statusand radiosensitivity in human tumour celll lines. $\mathrm{Br}$ J Cancer. 1996;73:581-8.

30. D anovaM , Giordano M , M azini G, Riccardi A. Expression of p53 protein during thecell cyclemeasured by flow cytometry in human leukemia. Leuk Res. 1990;14(5):417-22.

31. Faharat $N$, van der D P, Praxedes M , M orila R, M atutes E, C atovsky D. D emonstration of cytoplasmic and nuclear antigens in acute leukaemia using flow cytometry. J C lin Phatol. 1994;47:843-9.

32. Syrälä M T, Tiirikainen M , Jansson ST, Krusius T. Flow cytometry analysis of terminal deoxynucleotidyl transferase. A simplified method. Am J Clin Pathol. 1993;99:298303.

33. D rach $D, D$ rach J, G lassi $H, G$ attringer $C, H$ uber $H$. Flow cytometry detection of cytoplasmic antigens in acuteleukemias: implications for lineage assigment. Leuk Res. 1993;17(5):455-61.

34. Slaper-Cortenbach ICM , Admiraal LG, Kerr JM, van Leeuwen EF, von dem BorneAEGK, Tetteroo PA. Flowcytometry detection of terminal deoxynucleotidil transferase and other intracellular antigensin combination with membrane antigens in acute lymphatic leukemias. Blood. 1988;72(5):1639-44.

35. Young IT. Proof without prejudice: use of theKolmogorovSmirnov test for theanalysis of histograms from flow systems and other sources. J H istochem Cytochem.
1997;25(7):935-41.

36. Lampariello F. On the use of the Kolmogorov-Smirnov statistical test for immunofluorescence histogram comparasion. Cytometry. 2000;39:179-88.

37. Soussi T, D houcheK , Béroud C. p53 Webside and analysis of p53 gene mutations in human cancer: forging a link between epidemiology and carcinogenesis. $\mathrm{H}$ um $\mathrm{M}$ utat. 2000;15:105-13.

38. Tõnisson N , Zernant J, Kurg A, H endrik P, Slavim G, $H$ anno $R$, et al. Evaluating the arrayed primer extension resequencing assay of T P53 tumor suppressor gene. Proc $N$ at Acad Sci U S A. 2000;299:5503-8.

39. Rodrigues CS, deQ ueiros M GL, SalesVSF, Brito T N S, da Fonseca HEM , Paiva AS, et al. Estudo comparativo entre duas técnicas de contagem de subpopulação de células T em indivíduos infectadose não infectados com o vírus da imunodeficiência humana. Rev Bras Anal Clin. 2002;34(2):95-101.

40. $M$ aynadié $M$, Picard $F, H$ usson $B, C$ hatelain $B, C$ ornet $Y$, le Roux $G$, et al. Immunophenotypic clustering of myelodisplastic syndromes. Blood. 2002;100(7):2349-56.

41. Weir EG, Borowitz M J. Flow cytometry in thediagnosis of acuteleukemias. Semin H ematol. 2001;38(2):124-38.

42. Stetler-Stevenson M , Braylan RC. Flow cytometric analysis of lymphomasand lymphoproliferativedisorders. Semin H ematol. 2001;38(1):111-23.

43. Stetler-Stevenson M . N ovel methodsin detection of minimal residual non-H odgkin lymphoma. Cytotherapy. 1999;1:336-40.

44. M acey M G, M ccarthy DA, M ilene T, Cavenagh JD, $\mathrm{N}$ ewland AC. Comparative study of five commercial re agents for preparing normal and leukaemic lymphocytes for immunophenotype analysis by flow cytometry. Cytometry. 1999;38(4):153-60. 